\title{
O capitalismo verde rondando a Amazônia
}

\author{
PAULA, Elder Andrade de. Capitalismo verde e transgressões: Amazônia no \\ espelho de Caliban. Dourados: Ed. UFGD, 2013.
}

Jones Dari Goettert

Universidade Federal da Grande Dourados

Elder Andrade de Paula formou-se em Licenciatura em Ciências Agrícolas, pela Universidade Federal Rural do Rio de Janeiro, em 1983. Ali, na primeira metade da década de 1980, sobretudo volteado por leituras marxistas (com ênfase em Antonio Gramsci), foi se definindo como sujeito ao mesmo tempo teórico e militante, fazendo com que, imediatamente, após a conclusão da graduação, seguisse para a Amazônia, especificamente, o Acre, onde a fronteira agropecuária era empatada pelo movimento seringueiro, tendo à frente trabalhadores como Wilson Pinheiro e Chico Mendes. Junto com Sindicatos de Trabalhadores Rurais do Acre, foi se dando conta, ainda mais, da necessária articulação entre interpretação do mundo e seu fąimento, ou seja, a imprescindível articulação entre teoria e prática. A práxis o fez próximo da formação e dos embates iniciais da União dos Povos da Floresta e das primeiras formulações do que viria a se constituir como reservas extrativistas. Mas, caminhos são sempre de idas e voltas de um passo, dois passos... No final de 1988 percebe, e sente, radicalmente, a dramaticidade da luta de gentes trabalhadoras em meio a hegemonias locais, regionais, nacionais e internacionais: Chico Mendes é assassinado... Continuou, decisivamente, no acompanhamento do movimento sindical no Acre. Mas, no início dos anos 1990, já compreendia como, paulatinamente, a luta dos povos das florestas, das terras e das águas ia sendo sorrateiramente apropriada pelo discurso ambientalista, no qual a luta de classes e as contradições Capital x Trabalho desapareciam do horizonte dos novos projetos sobre a Amazônia, então propalados por "desenvolvimento sustentável". Em 1993, passa a compartilhar com a militância a condição de professor da Universidade Federal do Acre, já como mestre - com dissertação defendida ainda em 1991: Seringueiros e Sindicatos: um povo da floresta em busca da liberdade. Mas, é em 2003, com a tese (Des)envolvimento insustentável na Amazônia ocidental: dos missionários do progresso aos mercadores da natureza (publicada em livro pela Ed. UFAC), que passa a ser reconhecido, ao mesmo tempo, como um dos principais intérpretes das contradições do capitalismo na 
Amazônia brasileira e como persona non grata pelas elites políticas acreanas, dentre elas o "Governo da Floresta" do Partido dos Trabalhadores (apresentando-se ele mesmo como o braço institucional do avanço do novo capitalismo no Acre). Elder compreende, à frente dos próprios acontecimentos mais decisivos, que, além do assassinato físico de Chico Mendes, ocorria também seu assassinato simbólico, pois seu projeto de transformação radical da floresta em espaço de autonomia da classe trabalhadora é deposto. E, em seu lugar, inversamente, proliferam agora com ainda mais força a regulação, o controle e a subordinação. A mercantilização da natureza significa, poderosamente, a naturalização da mercantilização dos sonhos de "Chico", refletida pela aceleração do controle do capitalismo sobre os recursos e gentes da Amazônia. No entanto, o duplo assassinato de Chico Mendes não alimentou o medo, mas, justamente, a necessidade de compreensão ainda mais aguda dos processos e contradições na Amazônia. Elder já vinha construindo densas relações de trabalho e de luta em toda a Amazônia brasileira e, entre 2010 e 2011, estende-as à América Latina, seguindo para o México para seu pósdoutoramento, do qual este livro é sua produção principal.

Capitalismo verde e transgressões: Amazônia no espelho de Caliban é composto por dez capitulos, além da Introdução, das Considerações Finais e de um Prólogo, escrito por sua tutora de pós-doutoramento, Ana Esther Ceceña (UNAM/México). Nesse prólogo, uma pequena passagem aponta uma chave para toda análise da obra: "Los territórios no existen, se construyen...", aponta Ceceña. O sentido de Capitalismo verde e transgressões é justamente esse: uma análise densa e apurada sobre a construção de territórios na Amazônia, especificamente, entre a tríplice fronteira Brasil-Bolívia-Peru, explicitando os processos de afirmação da hegemonia capitalista, de um lado, e de transgressões, lutas e autonomias dos povos da floresta, da terra e da água, de outro. As partes da análise são: 1 - Esverdear o capitalismo para des-verdear a natureza; 2 - O PPG7 e Geopolítica na Amazônia brasileira: construindo bases avançadas de hegemonia; 3 - USAID e Geopolítica na Amazônia Continental; 4 - A fronteira tri-nacional Brasil/Bolívia/Peru; 5 Transgressões de fronteiras na era do capitalismo verde; 6 - Estado do Acre; 7 Departamento de Pando; 8 - Departamento de Madre de Dios; 9 - Brasil, IIRSA e hegemonia regional; e 10 - Marchando por autonomias na e além das fronteiras amazônicas.

Os processos que vêm definindo a afirmação da hegemonia capitalista sobre a Amazônia constituem temporalidades e espacialidades múltiplas. O processo histórico de invasão, dominação e exploração da Amazônia caminha pari passu à expansão, consolidação e metamorfoses do Modo de Produção Capitalista. Concentrando a análise nas últimas décadas, Capitalismo verde e transgressões não deixa de explicitar que a armação geopolítica do Capital reproduz, com suas variáveis práticas e discursivas, o que a Amazônia passa a representar com a exploração da borracha, nas décadas finais do século XIX e primeiras do século XX: o controle territorial, político, social, ideológico e simbólico sobre a classe 
trabalhadora, constituída por uma gama enorme de sujeitos, nativos e migrantes. Ideologicamente, a Amazônia é replantada a cada novo momento desse processo, com os epítetos que buscam conferir as legitimidades da espoliação: ocupação dos espaços vaz̧ios, progresso, integração, desenvolvimento e, nesta nova fase do capitalismo global, "desenvolvimento sustentável". Em todas as modalidades, as investidas, de fato, "des-envolvem" os povos das florestas, das terras e das águas. Contudo, e este é um dos pontos fulcrais do livro, o hegemon capitalista, em todos os momentos, se consolida articulando poderes multi-escalares: global, nacionais, regionais e locais. Ou seja, os consensos para a espoliação são consensos de uma classe, comandada globalmente, mas, com tentáculos formando uma rede de sustentação na exploração de "las bondades de la naturaleza", que atravessa Estados, governos, organizações não-governamentais (nacionais e estrangeiras) e até parte dos povos e sujeitos espoliados. A expansão e consolidação do capitalismo verde é o consenso de interesses que vai da escala global à local e que, em cada uma das unidades político-territoriais em análise - Acre, Pando, Madre de Dios dispõe de seus sócios menores: ocorre, no(s) território(s) transfronteiriço(s) trinacional(is), a armação imperialista do hegemon temporal (único, linear) e espacial (multiescalar, mas igualmente homogeneizante), anulando diferenças ou incorporando-as e neutralizando-as como conbecimentos empíricos da floresta.

Os processos de transgressões, lutas e autonomias dos povos das florestas, das terras e das águas, em suas múltiplas temporalidades e territorialidades, precisam, primeiro, conforme Elder Andrade de Paula, superar o maniqueísmo imposto pela lógica imperialista assentada no capitalismo verde: a escolba entre um "desenvolvimento sustentável" com práticas conservacionistas e um "desenvolvimento tradicional", com práticas de devastação e destruição da floresta. Essa superação pressupõe a construção de autonomias fora e longe das cores capitalistas e dentro e perto das experiências de vida indígenas e camponesas. Os movimentos sociais, nos territórios da tríplice fronteira, são diferentes em cada uma de suas partes. Mas, precisam atentar que, como o capitalismo verde transgride as fronteiras, o processo de apropriação da existência é semelhante. A luta pelas autonomias indígenas e camponesas precisa ser, também, transfronteiriça, como condição para a conquista das autonomias de fato. Cabe entender que o capitalismo verde se articula como imperialismo, associado a poderes oligárquicos, definindo colonialismos internos - como, por exemplo, em um capitalismo que, em vez de expulsar populações, torna-as subalternas a governanças sustentáveis e a manejos de toda espécie, em processo claro de fetichização da natureza, associada a um neopanóptico sobre os povos da Amazônia.

Assim, Capitalismo verde e transgressões: Amazônia no espelho de Caliban cumpre o que objetiva: se "Próspero", em A tempestade, de Willian Shakespeare, é o ser conquistador e colonizador, aqui, "Caliban", o escravo selvagem e disforme da peça do escritor inglês-europeu se volta contra a prosperidade, o progresso e o desenvolvimento. Porque, sem mais nem menos, são expressões e práticas apenas de uma 
fetichização avassaladora, retirando, usurpando e roubando dos bárbaros suas, ainda, potências de autonomias. Como aponta, em síntese, Elder Andrade de Paula: "ao contrário da imagem da Amazônia refletida no espelho de Próspero promessa de estabilidade aos povos indígenas e às comunidades camponesas, afiançada no reordenamento territorial, por meio da criação de 'áreas protegidas', e na edificação de uma base institucional, adaptada a uma modernidade comprometida com a 'participação democrática' e a 'conservação ambiental' -, aquela projetada no espelho de Caliban mostra uma realidade claramente oposta. [...] um quadro marcado pela erosão da autonomia desses povos na gestão de seus territórios e pelo agravamento da instabilidade socioeconômica, político-cultural e ambiental, num contexto de dominação marcado pelas transgressões emanadas de um Estado de exceção permanente e pela crescente militarização do território amazônico em escala continental".

Por isso, entendemos, a leitura de Capitalismo verde e transgressões: Amazônia no espelho de Caliban é imprescindível a todas e todos, bárbaras e bárbaros como o autor, que acreditam que a luta é processo necessário para a construção, contra a cor única do capital, de autonomias multicolores, indígenas, camponesas e de todas aquelas que tem a existência viva, humana, acima de qualquer forma de mercantilização.

Endereço para correspondência:

Jones Dari Goettert-jonesdari@hotmail.com

Rodovia Dourados, Itahum, Km 12

79804-970 Dourados/MS, Brasil 